ARTICLE

https://doi.org/10.1057/s41599-019-0254-5

\title{
Making the smart meter social promotes long-term energy conservation
}

\author{
Stefano De Dominicis ${ }^{1,2}$, Rebecca Sokoloski ${ }^{3}$, Christine M. Jaeger $^{4}$ \& P. Wesley Schultz ${ }^{4}$
}

\begin{abstract}
Managing demand for energy is becoming increasingly important for efforts to shift toward more sustainable lifestyles. Managing demand for energy involves changes in human behaviour, and can be achieved through more efficient uses of technology, and through conservation. Feedback is often cited as a critical tool to promote energy conservation and efficiency, but recent studies in behavioural science suggest that feedback alone may not be enough to promote lasting changes in behaviour. As an alternative, recent studies have shown the effectiveness of providing residents with normative feedback, rather than simple personal feedback. The current study analyses the impact of real-time feedback on residential electricity consumption over a two-year period. Results showed that when framed as a social comparison, feedback resulted in long-term reductions in household electricity consumption. Importantly, greater reductions were observed for households that identified more strongly with the normative referent group. Theoretical implications of the findings for behavioural science and the corresponding practical implications for fostering long-term sustainable behaviours are discussed.
\end{abstract}

\footnotetext{
${ }^{1}$ Department of Nutrition, Exercise and Sports, University of Copenhagen, Copenhagen, Denmark. ${ }^{2}$ CIRPA-Centro Interuniversitario di Ricerca in Psicologia Ambientale, Sapienza Università di Roma, Rome, Italy. ${ }^{3}$ Department of Environmental Conservation, University of Massachusetts, Amherst, MA, USA.

${ }^{4}$ Department of Psychology, California State University San Marcos, San Marcos, CA, USA. Correspondence and requests for materials should be addressed to S.D.D. (email: sdd@nexs.ku.dk)
} 


\section{Introduction}

- he United Nations' Conference on Climate Change (COP21) produced an ambitious international commitment to curtail global greenhouse gas emissions ('Paris Agreement - European Commission', 2015). Meeting this goal will require important critical changes to consumer behaviour patterns, in addition to changes to infrastructure and technology (IPCC, 2014; Karen, 2015). With electricity generation accounting for roughly $40 \%$ of global $\mathrm{CO}_{2}$ emissions, targeting this sector will be an important part of mitigating human impacts on the climate (Dietz et al., 2009). To achieve these changes, it is critical to understand how long-term sustainable behaviours can be promoted at the end-user level. Normative feedback has emerged as a useful tool in promoting energy efficiency and conservation, and to date has been successfully used with nearly 100 million households worldwide (e.g., opower.com). In contrast to personal feedback, which provides individuals with information about how their actions have changed over time, normative feedback provides individuals with information that allows them to compare their own behaviour to that of others.

In the current paper, we investigated the long-term effect of a normative feedback system in which residents' electricity use was compared to that of similar other households. The feedback was provided using smart meter enabled real-time in-home displays that provided dynamic information about household electricity consumption. The current paper builds on a previous study showing short-term energy reductions for households that received real-time normative feedback, but not for households that received simple personal feedback or feedback coupled with cost information (Schultz et al., 2015). In an effort to inform strategies aimed at achieving long-term sustainable behaviours we investigate the role of social-psychological factors in fostering conservation (Amel et al., 2017). Here we show that two years after the deployment of in-home displays, households receiving the normative feedback continued to use less electricity than did a randomized control. Importantly, the effect was stronger for households that more strongly identified with the referent group of 'similar households' used in the feedback frame.

\section{Resource conservation}

Behavioural science has identified a number of strategies for promoting energy conservation and efficiency. Recent work has begun to delineate the boundary conditions of each strategy, bringing to light the contexts in which each strategy is maximally effective at encouraging conservation behaviour (Schultz, 2015). Such strategies include commitments, financial appeals, incentives and disincentives, feedback, values-based messaging, and social norms (Abrahamse et al., 2007; Fielding et al., 2008; Schultz et al., 2007, 2005). In the area of energy conservation, monetary appeals have commonly been employed, with the underlying assumption that individuals will engage in a behaviour that has clear personal benefits (Penner et al., 2005). However, results on the effectiveness of financial appeals have been mixed. While some success has emerged by enticing or rewarding proenvironmental behaviour (Poortinga et al., 2013; Thøgersen, 2003), research has also shown a number of instances in which incentives have failed to promote, and in some cases even decreased, conservation behaviour (Asensio and Delmas, 2015; Schultz and Kaiser, 2012).

An increasingly common strategy to promote conservation behaviour involves highlighting a social norm. Following the actions of what most others are doing (descriptive norm) or believe ought to be done (injunctive norm) is a universal human tendency, and social norms have been shown to strongly influence a person's decisions (Cialdini, 2009, 2003). For instance, a non-littered environment conveys a descriptive normative message: people do not litter here. Likewise, a clean street with litter neatly swept into a pile communicates the injunctive normative message that others would disapprove of littering in this environment (Cialdini et al., 1991). Research has shown that normative messages are most influential when the descriptive and injunctive norms are aligned (e.g., a neighbourhood both practices recycling and disapproves of people who don't recycle). However, 'boomerang effects' (i.e., unintended reductions in the desired behaviour) can occur when individuals are provided with a descriptive norm that occurs at a lower rate than their current behaviour. For instance, someone who recycles often may reduce their recycling rates after learning that their neighbours recycle less than they do. To prevent this, an injunctive norm supporting the environmental behaviour can be leveraged (e.g., others approve of recycling; Schultz et al., 2007). This crucial aspect of injunctive and descriptive norms alignment has been showed in previous interventions based on normative campaigns, both in conservation behaviour such as household electricity consumption (Goldstein et al., 2008; Nolan et al., 2008), and, more broadly, across many pro-social behaviours (DiClemente et al., 2001; Keizer et al., 2013, 2008; Pillutla and Chen, 1999). In fact, through norms alignment, social norms can promote conservation behaviour among both those initially engaged and disengaged, alike. As described later, this alignment aspect is crucial in our study as well, because residents who are already conserving energy should be provided messages of approval for their continued low level of consumption. The approach of norms alignment is clearly linked with the core issue of the present research, namely promoting long-term sustainable lifestyles: in fact, sustained and aligned norms may function as promoters of increasingly well-performed pro-environmental and sustainable behaviours (Farrow et al., 2017); and, the worldwide explosion of social media in the last decade obviously provides fertile ground for applications able to reach millions of end-users (Schultz et al., 2018).

\section{Normative feedback and energy conservation}

While deviations from the norm is clearly evident for behaviours that occur in public (Griskevicius et al., 2010) (e.g., littering in public spaces), social norms are oftentimes unclear for private behaviours such as household electricity consumption, and the extent to which one's behaviour aligns with these norms. The latter obstacle comes about because households typically only receive energy use information via a utility bill that simply sums their usage; such feedback is spatially delayed, fails to highlight the most consumptive behaviours, and is often communicated in perceptually ambiguous units (e.g., kilowatt hours). Studies using various forms of feedback have been effective at increasing knowledge about consumptive behaviours (Kluger and DeNisi, 1996), as well as in promoting self-efficacy for reduced consumption (Bandura, 1986). In addition, studies have shown that coupling normative information with individualized feedback can reliably increase household conservation behaviours across several sectors, including recycling (Schultz, 1999), water (Schultz et al., 2014; Seyranian et al., 2015), and electricity (Grønhøj and Thøgersen, 2011; Schultz et al., 2015).

By providing households with normative feedback on a specified behavioural domain such as household electricity use, high consumers tend to decrease their consumption, aligning usage closer to the norm (Ferraro and Miranda, 2013; Ferraro and Price, 2013; Schultz et al., 2007). Targeting high-consumptive households is an effective strategy for generating overall energy reductions because even a small percentage reduction can outweigh the possible reductions that could be made by 
low-consuming households. Normative feedback is therefore a useful strategy for promoting sustainable behaviours, and it can generate substantial reductions in above-average users while keeping below-average users motivated to conserve.

While the efficacy of normative feedback has been clearly established, the durability of these changes is less clear. Some studies have only detected short-lived effects (Ferraro and Miranda, 2013; Fielding et al., 2008), and others have found sustained reductions (Allcott and Rogers, 2014, 2012; Ayres et al., 2012; Grønhøj and Thøgersen, 2011). In addition, the underlying mechanism for normative social influence has not been clearly established, although social identity theory would suggest that strong identification with the normative referent group could play an important role in the long-term impact of normative feedback.

\section{Group identification and conservation behaviours}

Because the worldwide environmental crisis results from the collective impact of individual choices, it is important to consider the collective or group-based drivers of behaviours (Fritsche et al., 2018). Social Identity Theory (Tajfel and Turner, 2004) proposes that individuals classify themselves and others into social groups, resulting in identification with the group (Ashforth and Mael, 1989; Tajfel and Turner, 2004). Membership to a group (ingroup) results in increased conformity with the perceived norms of the ingroup, while comparison to non-membership (outgroup) results in increased differentiation from the group (Turner et al., 1987). These two processes have been evidenced in the environmental literature (Fritsche et al., 2018): when one's ingroup is perceived to be relatively environmentally-oriented, individuals are more willing to engage in conservation behaviours. Conversely, when one's outgroup is perceived as less environmentally oriented, willingness to act pro-environmentally is lower (Ferguson et al., 2011; Graffeo et al., 2015).

Drawing on social identity theory, the influence of an ingroup should moderate the impact of normative feedback when identification with the referent group is high (Nigbur et al., 2010; Terry and Hogg, 1996). Previous research has established the attenuation of social influence when the referent group is perceived as an outgroup, but little direct evidence exists showing that the strength of identification with an ingroup can moderate the impact of a normative information (Abrams et al., 1990; Goldstein et al., 2008). While past research has focused on manipulating characteristics of the referent group to increase perceived similarity, here we measure participants' natural identification with the referent group to ascertain its impact in the normative influence paradigm.

\section{Fostering long-term energy conservation}

The current study expands on the results of Schultz and colleagues (Schultz et al., 2015) with new data. The initial analyses showed that smart-meter enabled in-home displays (IHDs) that provided normative feedback were effective in promoting energy conservation during a 3-month intervention. The new data reported here show kWh consumption for 390 homes over a twoyear period. We report two findings from a randomized experiment where we provided aligned descriptive and injunctive normative feedback (henceforth normative feedback). First, we corroborate and expand past research showing the persistence in energy reductions from a normative feedback intervention: providing aligned normative feedback is an effective strategy for promoting long-term energy conservation by reducing energy consumption among high users, and by providing social approval for continued conservation among low consuming households (e.g., mitigating the boomerang effect). Second, we demonstrate a novel moderating factor, group identification, that may explain the discrepant findings regarding the long-term effects of normative feedback.

\section{Method}

The methods reported here reflect those reported in Schultz and colleagues' study of 2015 (Schultz et al., 2015). Households were recruited from October 2012 to June 2013, and the intervention period began in July 2013. Household electricity data was provided by San Diego Gas and Electric (SDG\&E) utility, from July 2013 through September of 2015.

Participants. Residents of 390 single-family households participated in the study and had complete data for the entire study duration. About $76.2 \%$ reported earning more than $\$ 55,000$ per year (the identified regional median). The average household contained 3.41 residents, with an average residency of 11.1 years. Reported political affiliation was as follows: $35.9 \%$ Republican, $31.8 \%$ Democrat, and $24.9 \%$ other (note that these affiliations reflect only the individual who filled out the survey). Homes in the study averaged 2130 square feet, and those with photovoltaic solar panels were excluded.

\section{Materials}

Survey. Households were recruited for the study using both mail and follow-up in-person surveys. Survey items included several climate change and energy knowledge related questions, as well as demographics. The extent to which residents identified with households in their neighbourhood that were similar to their own was assessed by respondents rating the following statements from 1-7 (not true to very true): 'I am similar to this group', 'I see myself as part of this group', 'I am glad to belong to this group', and 'I feel that I have strong ties to this group' $(\alpha=.89)$. Consent was obtained via signature to collect electricity use data from SDG\&E utility company.

In-home displays. Rainforest Automation Company collaborated with our research team to create three distinct custom-coded inhome displays (IHDs; Fig. 1). Each device communicated near real-time energy use information via a display (3-5 sec delay), and three LED lights (red, yellow, and green). All displays depicted aggregated household energy use, and were wirelessly connected to the household's smart meter.

Feedback only. Feedback only IHDs communicated a household's near real-time energy consumption. Display lights changed colour as energy use in the home fluctuated past a 30\% threshold. A yellow light indicated that the electricity consumed in the home had not changed past that threshold within the past $3 \mathrm{~min}$. When the household increased its electricity use compared to the energy used in the past $3 \mathrm{~min}$, the light turned red. A green light indicated a reduction in energy use. Note that because the threshold was based on the past 3 min average energy consumption only, changes in energy consumption resulted in very clear injunctive normative information through near real-time feedback (3-5 sec delay) provided by the green or red light (social approval or disapproval).

Cost and feedback. The cost and feedback IHD showed the same information as the feedback only IHD, and also indicated the real-time cost associated with the household's energy use. SDG\&E's tiered pricing system was custom coded into the displays to ensure an accurate estimation of cost information. Although costs differed greatly between households, the typical household saw instantaneous costs in the 18-cent to 54-cent per hour range. The LED lights functioned the same as the lights on the feedback only IHD. 

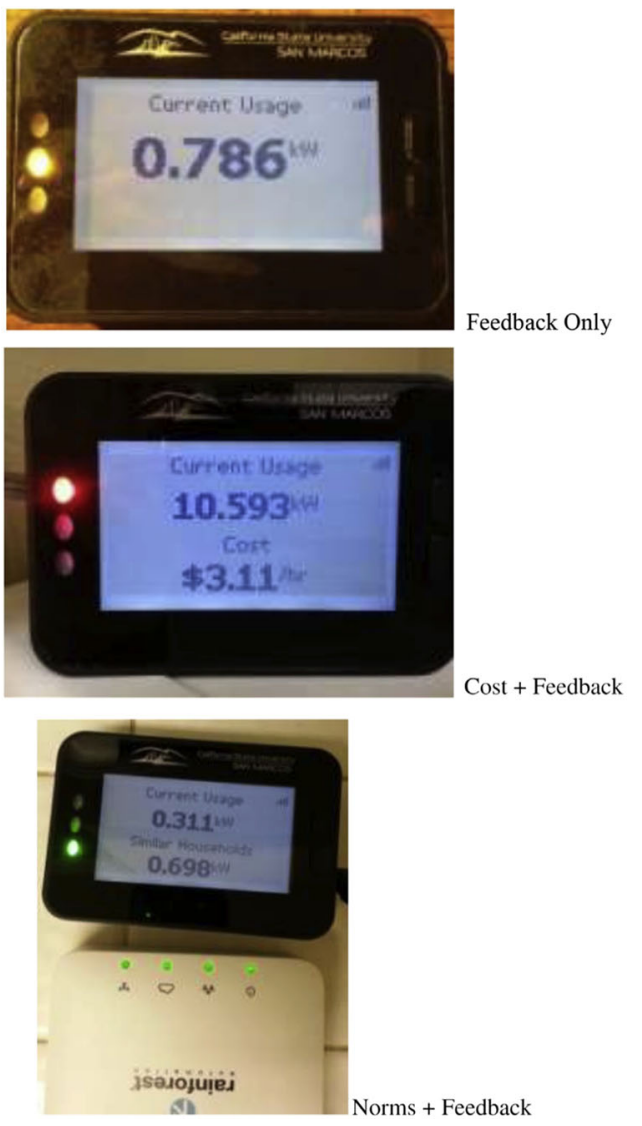

Fig. 1 In home displays (IHDs)

Norms and feedback. Participants who received the norms and feedback IHD were able to compare their current real-time energy use with that of the real-time averaged use of 'similar households in your neighbourhood'. The similar households' comparison was created using gateway technology and a data cloud to average the use of others in the study with a similar device. Following the same $30 \%$ threshold of the other devices, the LED lights reflected how the household's energy consumption compared to similar homes. The yellow light indicated a similar use, red a higher use, and green a lower use.

Procedure. Participants were recruited from an identified region of 6500 single-family homes in North County in San Diego, California. Using Zillow.com and Google maps, housing characteristics were recorded along with the postal addresses. This information was used to provide custom information on the survey, as well as additional data for analyses. Researchers initially followed the Tailored Design Method (Dillman, 2006), and also went door-to-door in order to increase response rates, resulting in an $18 \%$ positive response rate. Households that did not have Internet or refused to sign a data release form were excluded. Of the 1157 households who responded to the survey, 816 were eligible to participate.

The 816 participants were randomly assigned to 1 of 4 IHD conditions (feedback only, cost and feedback, norms and feedback, or no IHD). Participants were contacted by phone to schedule an installation date. Participants in the no IHD condition (control) were not given an IHD, but researchers visited them in their home, as well. (Note: this was due to the need to show some participants a video, not reported here; see Schultz et al., 2015 for details).
IHD deployments occurred over 4 weeks. A pair of researchers set up the devices in the home and explained features of the device to one or more household members. Participants were contacted 3 months following deployment to complete a followup survey over the phone (see Schultz et al., 2015 for details). Energy use data was obtained by SDG\&E via a passwordprotected computer. The research team followed strict protocol to protect participant information and the hourly kWh electricity data. Although 431 households were successfully recruited into the study, only 390 households had complete data for the longterm results reported here (e.g., residents moved, installed solar), with no differences in dropout rates across groups.

\section{Results}

Participants in this study were residents of single-family households, which used an average of $22.15 \mathrm{kWh}$ per day during the two weeks prior to the intervention (see methods section). Survey data from participating households were obtained prior to the experiment, among which included a measure of group identification with similar households in the area (operationalized as identification with 'households in your neighbourhood that are similar to yours'). In cooperation with Rainforest Automation, three different custom-coded in-home displays (IHDs) were developed. The three displays, plus the control group, were coded as follows:

1. Feedback-only IHD: displayed the household's current kW consumption

2. Feedback plus cost IHD: displayed current kW consumption and associated cost

3. Normative feedback IHD: displayed current kW consumption of household plus average $\mathrm{kW}$ consumption of similar neighbouring households that also had a normative feedback IHD

4. Control: participants did not receive an IHD

Each IHD had a digital display and three LED lights (red, yellow, and green), and was wirelessly connected with the smart meter in the participant's home. This wireless connection allowed for household $\mathrm{kW}$ consumption to be displayed on the IHD in near real time-approximately a $3-5 \mathrm{sec}$ delay. The LED lights provided valenced feedback to encourage reductions in energy consumption (see method section for details). For the feedbackonly and feedback plus cost IHDs, the green light was illuminated when the level of household consumption decreased; the yellow was illuminated when consumption did not change; and the red light was on when consumption increased. For the normative IHDs, the green light was on when household use was lower than the referent group (i.e., 'similar households'), yellow when use was the same, and red when electricity use was higher. In all conditions, these lights provided participants with an injunctive norm in relation to their current electricity use (e.g., red meant disapproval of higher energy use).

To calculate the effects of each treatment, overall average daily consumption of $\mathrm{kWh}$ across the two-year period between the groups was first analysed. Given the initial finding of a short-term reduction in energy consumption in the normative feedback condition (Schultz et al., 2015), we predicted a similar effect during the 2-year follow-up period. A oneway ANCOVA was conducted controlling for baseline consumption; a significant covariate effect was detected, $F(3,385)=624.20, p<.001$, $p \eta^{2}=.62$, and no main effect of treatment was found, $F(3$, $385)=.98, p>.05, p \eta^{2}=.01$ (see Fig. 2 for marginal means). Given our a priori prediction, a protected planned comparison (Howell, 2012) was conducted, revealing that households in the normative feedback condition $(M=20.69 ; \mathrm{SD}=9.79 ; N=80)$ 
consumed less electricity on a daily average at a marginally significant level compared to the average of the households that received either standalone feedback, cost feedback, or no feedback (control) $\quad(M=21.68 ; \quad \mathrm{SD}=8.99 ; \quad N=310), \quad t(387)=1.40$, $p=.081, d=.18$. Households that received normative feedback used $4.57 \%$ less electricity across the 2 -year period than did the other three experimental groups. These encouraging results suggest that normative feedback may result in both immediate and long-term energy reductions (see Figs. 2 and 3).

Because normative feedback promoted the greatest reductions in energy use across the two years, we conducted further analyses and tested our main hypothesis: that identification with the referent group (similar households) would moderate the relationship between normative feedback and long-term energy consumption, with households highly identified with the referent group demonstrating the most durable energy use reductions. In these focused analyses, we compared the normative feedback condition to the other three groups combined. Combining the non-normative groups was justified because (a) the normative

\section{Average kWh consumption across conditions}

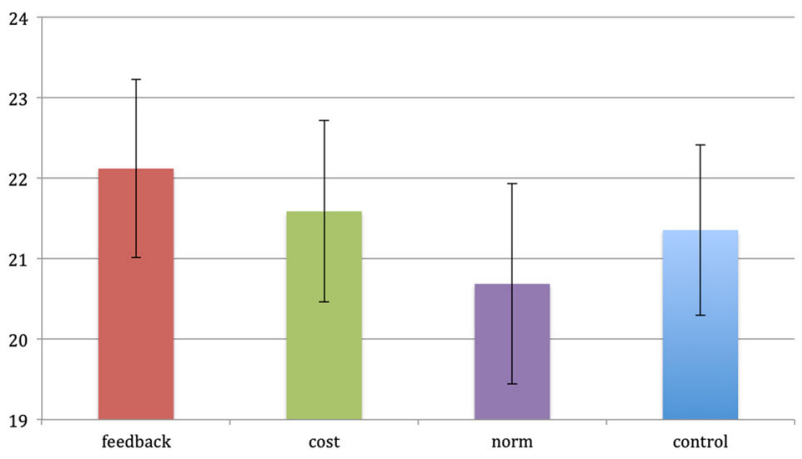

Fig. 2 Average daily kWh consumption across experimental conditions in the two-years period. DV (y-axis) represents overall aggregated daily $\mathrm{kWh}$ consumption across two years in $\mathrm{kWh}$ (from $19 \mathrm{kWh}$ to $24 \mathrm{kWh}$ ). Error bars represent a $95 \%$ C.I comparison occurred only in the normative feedback condition, and (b) there were no significant differences in energy use between the three non-norm conditions in the short term. A moderation analysis was conducted using PROCESS (Hayes, 2013) and allowed us to test our hypothesis using a dichotomous independent variable (normative feedback vs. other conditions combined) and a continuous moderator (i.e., the full range of identification scores) to predict the criterion variable (i.e., average daily kWh consumption aggregated at the weekly level during the 2year follow-up period), while controlling for baseline consumption. Results, computed using robust standard error to correct for heteroskedasticity (Breusch-Pagan: $L M=22.45, p<.001$; Koenker: $L M=12.39, p=.01$ ), showed that our model significantly predicted the criterion variable, $F(4,379)=186.57, p>.001, R_{\text {adj }}^{2}=.63$. Baseline energy consumption was a significant covariate, $b=.72$, $t=26.16, p<.001$. Importantly, the interaction term was marginally significant, $b=-.69, t=-1.85, p=.06$. Given our a priori hypothesis, we proceeded to probe the interaction through a spotlight analysis and through the Johnson-Neyman technique (Johnson and Fay, 1950). Specifically, we report conditional effects of the normative condition on long-term energy consumption for low identification ( -1 standard deviation), average identification (mean) and high identification (+1 standard deviation) with similar households. Results show that the strength of the effect increases for higher scores of identification with similar households. Controlling for baseline energy consumption, this indicates that as identification with similar household strengthens, normative feedback exhibits a stronger effect on long-term energy conservation (Fig. 4), respectively with low identification $(M=3.10, b=-.02, t=-.03, p=.97)$, average identification $(M=4.63, b=-1.08, t=-1.62, p=.11)$, and high identification $(M=6.17, b=-2.14, t=-2.27, p=.02)$.

The full range of conditional effects are plotted in Fig. 5 using the Johnson-Neyman technique (Hayes and Montoya, 2017), showing that the conditional effect of normative feedback on long-term $\mathrm{kWh}$ consumption through identification with similar households is significant for the top $37.24 \%$ of identifiers. Overall, these results suggest that increased identification with the reference group enacts the desired sustainable behaviour (in our case,

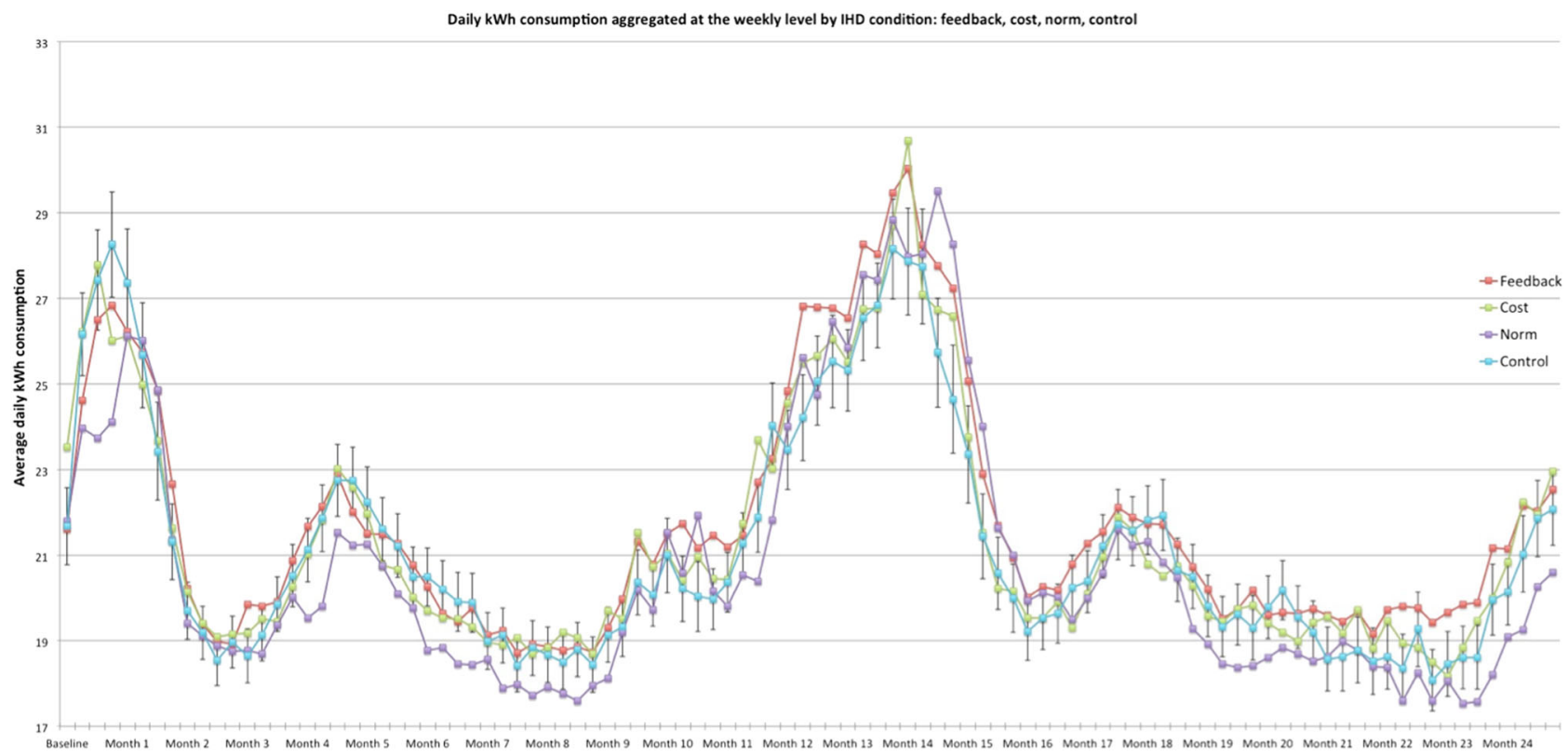

Fig. 3 Average daily kWh consumption across experimental conditions for the 2-years period. Marginal means are shown for each experimental condition (standalone feedback, cost feedback, normative feedback, control). Error bars represent the standard error the control group' marginal means resulting from an oneway repeated measures ANCOVA (IHD condition on average daily energy consumption; covariate: baseline kWh consumption) 
energy conservation) in the context of receiving normative feedback on the behaviour of similar households. In other words, the more individuals are identified with a referent group for which they receive aligned descriptive and injunctive normative feedback, the more they will conserve energy.

\section{Discussion}

Results from 2 years of smart meter data showed that normative feedback interventions can successfully promote long-term energy reductions, and that these reductions are largely realized by households that are more strongly identified with the normative referent group. To our knowledge, this finding is the first to establish support for the positive moderating role of group identification in the normative influence paradigm, as well as the first to measure these effects long-term.

The durability of the normative feedback effects in this intervention corroborate the findings of other long-term analyses (Allcott and Rogers, 2012; Ayres et al., 2012; Grønhøj and Thøgersen, 2011), affirming the viability of this tool in promoting sustained reductions in residential energy use. These findings indicate that normative feedback may facilitate the development

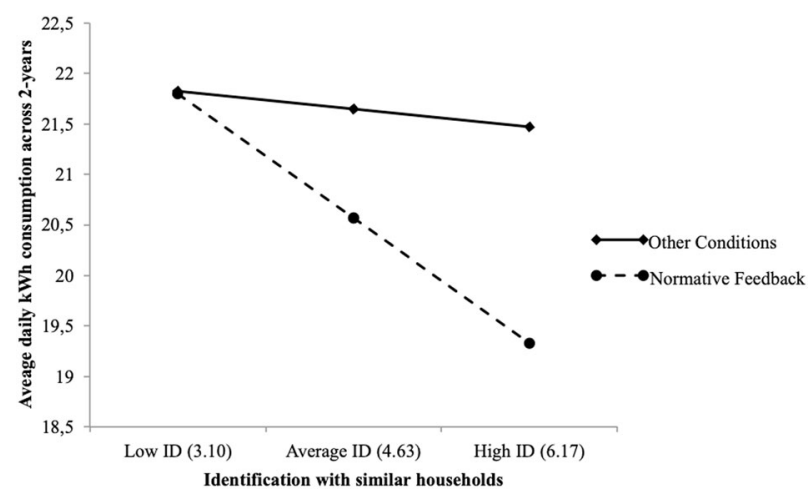

Fig. 4 Spotlight analysis probing the interaction effect of IHD condition and identification with similar households on average daily kWh consumption. The conditional effect of the normative condition on long-term energy consumption is shown for low identification ( -1 standard deviation), average identification (mean) and high identification ( +1 standard deviation) with similar households. The slopes are significantly different at a $95 \%$ Confidence Interval of an energy conservation-oriented identity. The development of such an identity may mediate the relationship between a normative feedback intervention and the durability of its effects. To our knowledge, we provide the first support that group identification, long proposed as a theoretically sound moderator (Fritsche et al., 2018; Schultz et al., 2018), indeed moderates the relationship between normative influence and long-term energy reductions. This finding suggests that, while normative information regarding a generic group exerts a strong influence on behaviour, normative information pertaining to one's in-group may be even more effective in promoting durable behaviour change. Therefore, we provide here a theoretically sound and practically effective framework to promote widespread sustainability. In fact, this framework, rooted in latest research in environmental and social psychology, could be easily applied thank to the actual technological advancements we are developing and using worldwide (e.g., social networks, smart meters, internet of things, etc.; Fritsche et al., 2018; Schultz et al., 2018). However, because past research has struggled to manipulate referent group characteristics to increase perceived identification with the ingroup (Goldstein et al., 2008), future research should investigate which factors in which populations are most likely to promote group identification.

In application, we suggest that while real-time feedback is an effective strategy, standalone feedback without context is less effective in promoting long-term reductions compared to coupling the feedback with normative information. Secondly, the finding that those highly identified with the referent group tended to sustain energy reductions offers a powerful potential tool for companies already implementing normative feedback interventions, such as Opower (Schultz et al., 2018). It should follow that communications enhancing the perceived group affiliation with a low-consuming referent group could motivate high-consuming households to reduce their consumption and lead to sustained reductions. What's more, it could be possible to promote collective pro-environmental action at the community level by reinforcing the identification and belongingness to a 'green community'. Continued research on the factors that promote ingroup identity in the normative influence paradigm would complement these findings. Furthermore, long-term sustainable behaviours (e.g., energy conservation) could be further enhanced if tailored for specific groups of individuals (e.g., groups of endusers) or if targeting specific times across the year (e.g., winter vs. summer, heat-waves and drought periods). In Fig. 3, we split the

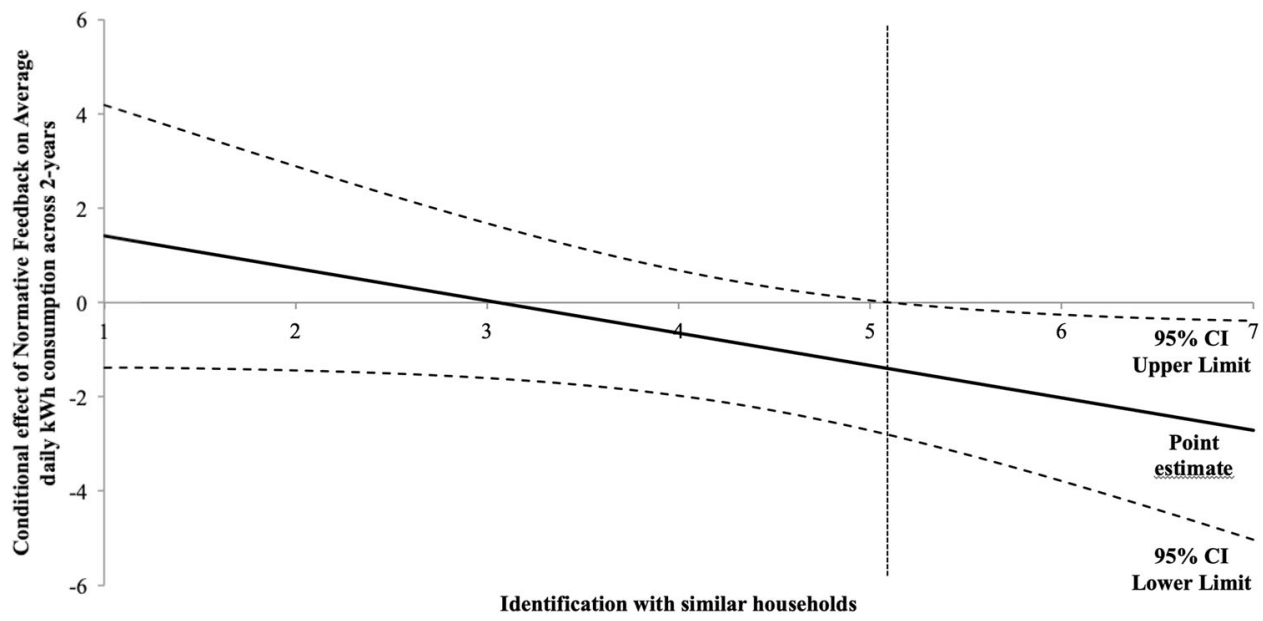

Fig. 5 Johnson-Neyman technique showing the full range of conditional effect of normative feedback on long-term kWh consumption through identification with similar households. The effect is significant for the top $37.24 \%$ of identifiers at a $95 \%$ Confidence Interval 
reduction effect of the three experimental conditions and the control group and span it across the 2-years period showing marginal means (and significant differences through error bars) of the average daily $\mathrm{kWh}$ consumption. As an applied example, which should be further investigated in the future, such in depth analysis could inform future policies and interventions to foster even more long-term energy conservation, as well as other possible sustainable behaviours.

Given the pressing need to mitigate global carbon emissions, changes in consumer behaviours are needed alongside structural solutions for the translation of behavioural science into interventions (Allcott and Mullainathan, 2010), although focusing on the time pressure issue for sustainability promotion could eventually turn out as a non-winning strategy (Brozyna et al., 2018). Instead, according to the evidence reported here, a simple addition to the already widespread smart meter technology-conveying a social comparison to a relevant referent group-or costand resources-effective applications through social networks or internet of things, offer readily implementable strategies to promote long-term energy reductions. Because the normative feedback strategy is feasible in implementation, targets specific groups of end-users, and promotes a culture of sustainability, it warrants serious consideration as a primary tool in curbing sustainable behaviours such as considerate energy use particularly among households with strong ties to relevant reference groups.

\section{Data availability}

Anonymized survey data and dwelling data are available by request from the corresponding author. The smart meter data regarding household electricity consumption were obtained through a data-sharing agreement with our regional utility, San Diego Gas and Electric (SDG\&E), and as such, due to the terms of the legal agreement, are not publicly available.

Received: 27 July 2018 Accepted: 15 April 2019

Published online: 21 May 2019

\section{References}

Abrahamse W, Steg L, Vlek C, Rothengatter T (2007) The effect of tailored information, goal setting, and tailored feedback on household energy use, energy-related behaviors, and behavioral antecedents. J Environ Psychol 27:265-276. https://doi.org/10.1016/j.jenvp.2007.08.002

Abrams D, Wetherell M, Cochrane S, Hogg MA, Turner JC (1990) Knowing what to think by knowing who you are: self-categorization and the nature of norm formation, conformity and group polarization. Br J Soc Psychol 29:97-119. https://doi.org/10.1111/j.2044-8309.1990.tb00892.x

Allcott H, Mullainathan S (2010) Behavior and energy policy. Science 327:1204-1205. https://doi.org/10.1126/science.1180775

Allcott H, Rogers T (2014) The short-run and long-run effects of behavioral interventions: experimental evidence from energy conservation. Am Econ Rev 104:3003-3037. https://doi.org/10.1257/aer.104.10.3003

Allcott H, Rogers TT (2012) How long do treatment effects last? Persistence and durability of a descriptive norms intervention's effect on energy conservation HKS Faculty Research Working Paper Series RWP12-045, John F. Kennedy School of Government, Harvard University

Amel E, Manning C, Scott B, Koger S (2017) Beyond the roots of human inaction: Fostering collective effort toward ecosystem conservation. Science 356:275-279. https://doi.org/10.1126/science.aal1931

Asensio OI, Delmas MA (2015) Nonprice incentives and energy conservation. Proc Natl Acad Sci 112:E510-E515. https://doi.org/10.1073/pnas.1401880112

Ashforth BE, Mael F (1989) Social identity theory and the organization. Acad Manag Rev 14:20-39. https://doi.org/10.5465/AMR.1989.4278999

Ayres I, Raseman S, Shih A (2012) Evidence from two large field experiments that peer comparison feedback can reduce residential energy usage. J Law Econ Organ. https://doi.org/10.1093/jleo/ews020

Bandura A (1986) Social foundations of thought and action: a social cognitive theory. Prentice Hall, Englewood Cliffs, NJ
Brozyna C, Guilfoos T, Atlas S (2018) Slow and deliberate cooperation in the commons. Nat Sustain 1:184-189. https://doi.org/10.1038/s41893-018-0050-z Cialdini RB (2009) Influence: science and practice. Pearson Education, Boston, MA Cialdini RB (2003) Crafting normative messages to protect the environment. Curr Dir Psychol Sci 12:105-109. https://doi.org/10.1111/1467-8721.01242

Cialdini RB, Kallagren CA, Reno RR (1991) A focus theory of normative conduct: A theoretical refinement and reevaluation of the role of norms in human behavior. Adv Exp Soc Psychol 24:201-234. https://doi.org/10.1016/S00652601(08)60330-5

DiClemente CC, Marinilli AS, Singh M, Bellino LE (2001) The role of feedback in the process of health behavior change. Am J Health Behav 25:217-227. https://doi.org/10.5993/AJHB.25.3.8

Dietz T, Gardner GT, Gilligan J, Stern PC, Vandenbergh MP (2009) Household actions can provide a behavioral wedge to rapidly reduce US carbon emissions. Proc Natl Acad Sci 106:18452-18456. https://doi.org/10.1073/ pnas. 0908738106

Dillman DA (2006) Mail and internet surveys: the tailored design method-2007 update with new internet, visual, and mixed-mode guide. Wiley, Hoboken, N

Farrow K, Grolleau G, Ibanez L (2017) Social norms and pro-environmental behavior: a review of the evidence. Ecol Econ 140:1-13. https://doi.org/ 10.1016/j.ecolecon.2017.04.017

Ferguson MA, Branscombe NR, Reynolds KJ (2011) The effect of intergroup comparison on willingness to perform sustainable behavior. J Environ Psychol 31:275-281. https://doi.org/10.1016/j.jenvp.2011.04.001

Ferraro PJ, Miranda JJ (2013) Heterogeneous treatment effects and mechanisms in information-based environmental policies: evidence from a large-scale field experiment. Resour Energy Econ 35:356-379. https://doi.org/10.1016/j. reseneeco.2013.04.001

Ferraro PJ, Price MK (2013) Using nonpecuniary strategies to influence behavior: evidence from a large-scale field experiment. Rev Econ Stat 95:64-73. https:// doi.org/10.1162/REST_a_00344

Fielding KS, McDonald R, Louis WR (2008) Theory of planned behaviour, identity and intentions to engage in environmental activism. J Environ Psychol 28:318-326. https://doi.org/10.1016/j.jenvp.2008.03.003

Fritsche I, Barth M, Jugert P, Masson T, Reese G (2018) A social identity model of pro-environmental action (SIMPEA). Psychol Rev 125:245-269. https://doi. org $/ 10.1037 /$ rev0000090

Goldstein NJ, Cialdini RB, Griskevicius V (2008) A room with a viewpoint: using social norms to motivate environmental conservation in hotels. J Consum Res 35:472-482. https://doi.org/10.1086/588568

Graffeo M, Ritov I, Bonini N, Hadjichristidis C (2015) To make people save energy tell them what others do but also who they are: a preliminary study. Front. Psychol. https://doi.org/10.3389/fpsyg.2015.01287

Griskevicius V, Tybur JM, Van den Bergh B (2010) Going green to be seen: status, reputation, and conspicuous conservation. J Pers Soc Psychol 98:392-404. https://doi.org/10.1037/a0017346

Grønhøj A, Thøgersen J (2011) Feedback on household electricity consumption learning and social influence processes. Int J Consum Stud 35:138-145. https://doi.org/10.1111/j.1470-6431.2010.00967.x

Hayes AF (2013) Introduction to mediation, moderation, and conditional process analysis: a regression-based approach. Guilford Press, New York, NY

Hayes AF, Montoya AK (2017) A tutorial on testing, visualizing, and probing an interaction involving a multicategorical variable in linear regression analysis. Commun Methods Meas 11:1-30. https://doi.org/10.1080/19312458.2016. 1271116

Howell DC (2012) Statistical methods for psychology. Cengage Learning, Belmont, CA

IPCC (2014) Climate change 2014: mitigation of climate change. Contribution of Working Group III to the Fifth Assessment Report of the Intergovernmental Panel on Climate Change. Cambridge University Press, Cambridge, UK and New York, USA

Johnson PO, Fay LC (1950) The Johnson-Neyman technique, its theory and application. Psychometrika 15:349-367. https://doi.org/10.1007/BF02288864

Karen O (2015) Political agency: the key to tackling climate change. Science. https://doi.org/10.1126/science.aad0267

Keizer K, Lindenberg S, Steg L (2013) The importance of demonstratively restoring order. PLoS ONE 8:e65137. https://doi.org/10.1371/journal.pone.0065137

Keizer K, Lindenberg S, Steg L (2008) The spreading of disorder. Science 322:1681-1685. https://doi.org/10.1126/science.1161405

Kluger AN, DeNisi A (1996) The effects of feedback interventions on performance: A historical review, a meta-analysis, and a preliminary feedback intervention theory. Psychol Bull 119:254-284. https://doi.org/10.1037/0033-2909. 119.2.254

Nigbur D, Lyons E, Uzzell D (2010) Attitudes, norms, identity and environmental behaviour: using an expanded theory of planned behaviour to predict participation in a kerbside recycling programme. Br J Soc Psychol 49:259-284 https://doi.org/10.1348/014466609X449395 
Nolan JM, Schultz PW, Cialdini RB, Goldstein NJ, Griskevicius V (2008) Normative social influence is underdetected. Pers Soc Psychol Bull 34:913-923. https://doi.org/10.1177/0146167208316691

Paris Agreement-European Commission (2015) [WW Document] UR. http://ec. europa.eu/clima/policies/international/negotiations/paris/index_en.ht. Accessed 7 Apr 2016

Penner LA, Dovidio JF, Piliavin JA, Schroeder DA (2005) Prosocial behavior: multilevel perspectives. Annu Rev Psychol 56:365-392. https://doi.org/ 10.1146/annurev.psych.56.091103.070141

Pillutla MM, Chen X-P (1999) Social norms and cooperation in social dilemmas: the effects of context and feedback. Organ Behav Hum Decis Process 78:81-103. https://doi.org/10.1006/obhd.1999.2825

Poortinga W, Whitmarsh L, Suffolk C (2013) The introduction of a single-use carrier bag charge in Wales: attitude change and behavioural spillover effects. J Environ Psychol 36:240-247. https://doi.org/10.1016/j.jenvp.2013.09.001

Schultz PW (2015) Strategies for promoting proenvironmental behavior. Eur Psychol 19:107-117. https://doi.org/10.1027/1016-9040/a000163

Schultz PW (1999) Changing behavior with normative feedback interventions: a field experiment on curbside recycling. Basic Appl Soc Psychol 21:25-36. https://doi.org/10.1207/s15324834basp2101_3

Schultz PW, Estrada M, Schmitt J, Sokoloski R, Silva-Send N (2015) Using in-home displays to provide smart meter feedback about household electricity consumption: A randomized control trial comparing kilowatts, cost, and social norms. Energy 90 (Part 1):351-358. https://doi.org/10.1016/j.energy.2015. 06.130

Schultz PW, Gouveia VV, Cameron LD, Tankha G, Schmuck P, Franěk M (2005) Values and their relationship to environmental concern and conservation behavior. J Cross-Cult Psychol 36:457-475. https://doi.org/10.1177/00220 22105275962

Schultz PW, Kaiser FG (2012) Promoting proenvironmnetal behavior. In: Clayton $S$ (Ed.) Handbook of environmental psychology. Oxford University Press, Oxford, UK, pp 556-580

Schultz PW, Messina A, Tronu G, Limas EF, Gupta R, Estrada M (2014) Personalized normative feedback and the moderating role of personal norms: a field experiment to reduce residential water consumption. Environ Behav https://doi.org/10.1177/0013916514553835

Schultz PW, Nolan JM, Cialdini RB, Goldstein NJ, Griskevicius V (2018) The constructive, destructive, and reconstructive power of social norms: reprise. Perspect Psychol Sci 13:249-254. https://doi.org/10.1177/1745691617693325

Schultz PW, Nolan JM, Cialdini RB, Goldstein NJ, Griskevicius V (2007) The Constructive, destructive, and reconstructive power of social norms. Psychol Sci 18:429-434. https://doi.org/10.1111/j.1467-9280.2007.01917.x

Seyranian V, Sinatra GM, Polikoff MS (2015) Comparing communication strategies for reducing residential water consumption. J Environ Psychol 41:81-90. https://doi.org/10.1016/j.jenvp.2014.11.009

Tajel H, Turner JC (2004) The social identity theory of intergroup behavior. In: Jost JT, Sidanius J (Eds) Political psychology: key readings, key readings in social psychology. Psychology Press, New York, NY, US, pp 276-293

Terry DJ, Hogg MA (1996) Group norms and the attitude-behavior relationship: a role for group identification. Pers Soc Psychol Bull 22:776-793. https://doi. org/10.1177/0146167296228002
Thøgersen J (2003) Monetary incentives and recycling: behavioural and psychological reactions to a performance-dependent garbage fee. J Consum Policy 26:197-228. https://doi.org/10.1023/A:1023633320485

Turner JC, Hogg MA, Oakes PJ, Reicher SD, Wetherell MS (1987) Rediscovering the social group: a self-categorization theory. Basil Blackwell, Cambridge, MA, US

\section{Acknowledgements}

The original experimental research that provided the foundation for this paper was funded by a grant from the National Science Foundation (DUE-1239797). The initial project was part of the Climate Education Partnership at the University of San Diego, led by Michel Boudrias, Mica Estrada, Sasha Gershunov, and Nilmini Silva-Send. The implementation was conducted with a large team at CSUSM, including Anela AmbaPascua, Maria Aguilar, Andrea Briseno, Mariah Parvizi, Nicholas Roome, Perla Sandoval, Sierra Schultz, Kayla Sinfield, Jenna Szuch, and Danielle Teece. We acknowledge the support of San Diego Gas and Electric (SDG\&E), and the staff including Tyler Sybert, Tishmari Lewis, and Nenita Plorin. The in-home displays used in the reported experiment were developed by Rainforest Automation, and we acknowledge the help of Chris Tumpach.

\section{Additional information}

Competing interests: The authors declare no competing interests.

Ethical approval: The present study and analyses were approved by the Institutional Review Board at California State University, San Marcos. Signed informed consent was obtained from all participants.

Reprints and permission information is available online at http://www.nature.com/ reprints

Publisher's note: Springer Nature remains neutral with regard to jurisdictional claims in published maps and institutional affiliations.

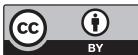

Open Access This article is licensed under a Creative Commons Attribution 4.0 International License, which permits use, sharing, adaptation, distribution and reproduction in any medium or format, as long as you give appropriate credit to the original author(s) and the source, provide a link to the Creative Commons license, and indicate if changes were made. The images or other third party material in this article are included in the article's Creative Commons license, unless indicated otherwise in a credit line to the material. If material is not included in the article's Creative Commons license and your intended use is not permitted by statutory regulation or exceeds the permitted use, you will need to obtain permission directly from the copyright holder. To view a copy of this license, visit http://creativecommons.org/ licenses/by/4.0/.

(c) The Author(s) 2019 